
\title{
R Reserach S Suare \\ Knowledge, attitude and practice regarding therapeutic communication among nurses in Kandy District, Sri Lanka
}

\section{Dilrukshi Dissanayake}

University of Peradeniya Faculty of Allied Health Sciences

Rasika Manori jayasinghe ( $\triangle$ manorija@pdn.ac.lk)

University of Peradeniya Faculty of Dental Sciences https://orcid.org/0000-0001-5878-4985

Sachith Abeysundara

University of Peradeniya Faculty of Science

Research article

Keywords: knowledge, attitude, practice, therapeutic communication, nurses.

Posted Date: August 19th, 2019

DOl: https://doi.org/10.21203/rs.2.13128/v1

License: (c) (i) This work is licensed under a Creative Commons Attribution 4.0 International License.

Read Full License 


\section{Abstract}

Background Therapeutic communication is considered as a skill required for all health care workers in order to improve understanding the patient in a better manner and encouraging the patient to express feelings \& ideas. It has also been accepted as a high standard of nursing care which is to be practiced at every hospital and nursing facility. As practice of therapeutic communication improves outcome of nursing care, objective of this study was to assess the level of knowledge, attitude and practice regarding therapeutic communication among nurses in teaching hospitals in the Kandy district, Sri Lanka. Specific objectives were to determine the factors affecting practice of therapeutic communication and to evaluate the self- satisfaction of therapeutic communication among participants. Methods A cross sectional study design was employed to gather data by a structured self-administered questionnaire involving 200 nurses working in teaching hospitals in Kandy, Sri Lanka. Results were analyzed by MINITAB version 18. Results Around $63.63 \%$ nurses were strongly favorable towards the fact that active listening is the most important part in therapeutic communication between patient and the nurse. The majority of participants were with the attitude that therapeutic communication prevents medical errors which could occur when treating patients. Fifty-nine percent of nurses always applied therapeutic communication in pre-operative \& post-operative care. There was a statically significant association between socio-demographic variables and knowledge, attitudes and practice of therapeutic communication among the study population. Majority agree to promote the therapeutic communication in their clinical setting. However, increased workload at the hospital was named a barrier by many participants. Conclusions A statistically significant association exists between educational status,position \& number of years in service and knowledge, attitude \& practice of therapeutic communication. Active listening is considered the most important part in therapeutic communication which prevents medical errors of patients. Majority agree to promote the practice in their clinical setting, but consider that it would increase their workload. Findings reveal the necessity of introducing awareness programs and workshops preferably by the authorities concerned highlighting advantages of applying therapeutic communication in the nursing practice.

\section{Background}

Communication is explained as transmission of messages from the sender to the recipient which gives a lot of benefits for both parties namely; receiving and providing information, problem solving, sharing pleasure, providing relaxation \& and some kind of control over the other people. Communication skills are valuable in the development and progress of health settings(Profile, 2017).

Therapeutic communication skills for the nurses are focused towards better understanding of patients through verbal \& non-verbal methods. It further supports in establishing a relationship of trust \& mutual cooperation between nurses \& patients(Profile, 2017).Furthermore, therapeutic communication encourages the patient to express feelings \& ideas with the opportunity to convey acceptance \& respect in verbal \& non- verbal manner (Sherko et al., 2013).Moreover, therapeutic communication is also considered an important factor when assessing quality of health care (Younis et al., 2015) and has been recognized as fundamental to all nursing practice (Miguel et al., 2014). 
Further it is a requirement that the nurse and patient collaborate actively following different types of communication, such as active listening by paying attention to what the patient is saying verbally $\&$ non verbally. A nurse can help patient to express emotions by making observations. Touch is considered as one of the most powerful form of therapeutic communication and can be explained as bringing the sense of caring by holding a patient's hand, using silence allowing the patient to think \& gain some insight into the situation. (Sherko et al.2013).Communication skills support in providing information \& feedback, giving hope to patient and helping them to cope with anxiety during hospitalization (Shafakhah et al.,2015). Nurses could provide a higher patient satisfaction, better health outcomes, quality of treatment care \& more active self -management in patients with chronic diseases when they apply therapeutic communication for their patients(Ferreira et al.,2016). On the other hand, ineffective communication could result in stress, errors in diagnosis, decrease of patient participation in care plan \& information exchange and poor quality of treatment outcome(Shafakhah et al.,2015).

There has been wide discussion among health care workers regarding the quality of outcome in the patient care in hospital settings. One of the aspects which has drawn attention by various centers and researchers was to investigate knowledge, attitude and practice of effective and appropriate communication between the nurses and patients as patients spend most of their hospital stay with nurses in the clinics and wards. As positive effects of therapeutic communication have been identified, multiple research in the field have been conducted in order to find the possibilities of further improving practice of therapeutic communication by the nurses.

The current challenge in health care is to create a suitable environment for the transparent communication. Promoting effective communication in health care is complex \& challenging due to the nature of hospital environment. The current state hospital environment is often stressful \& pressurized owing to high demand for free health service. Therefore, nurses need to be supported by high-quality and evidence based training in order to meet those challenges (Bramhall et al., 2015).

Outcome of this study would be helpful for the nurses to improve their knowledge, attitude \& practice for improved quality of care $\&$ to identify the causes of failure in therapeutic communication in these hospitals. As we could not trace any peer reviewed article in the area of study in Kandy district in Sri Lanka, it is expected that the outcome of this study will provide significant information on identification of specific problem areas which need to be improved in the future. It further will support in enhancing physical as well as psychological wellbeing of the patients in the state hospitals in the region. It ultimately will uplift the quality of care at the state hospital sector in the country.

\section{General Objective}

To determine the knowledge, attitude \& practice regarding therapeutic communication among nurses in Teaching Hospitals in Kandy district.

\section{Specific Objectives}


1. To determine level of knowledge of therapeutic communication among nurses in Teaching hospitals in Kandy district.

2. To determine level of attitude of therapeutic communication among participants.

3. To describe the percentage of participants currently applying therapeutic communication in Teaching hospitals in Kandy district.

4. To determine the factors affecting practice of therapeutic communication in Teaching Hospitals in Kandy district.

5. To evaluate the self- satisfaction of therapeutic communication among participants.

\section{Methods}

\section{Study design}

The study was conducted as a survey research design to assess knowledge, attitudes and practice regarding therapeutic communication among nurses in teaching hospitals in Kandy district. A descriptive cross-sectional study was carried out with a self-administered questionnaire.

\section{Study area/setting}

The study was conducted at Teaching Hospitals in Kandy district (Teaching hospital Peradeniya, Sirimavo Bandaranaike Specialized Children's Hospital \&Teaching hospital Kandy).

\section{Study population}

The study population was nurses attached to teaching hospitals in Kandy district with more than 6 months of service in the respective hospital.

- Inclusion Criteria- Nurses with 6 months or more service in the respective hospital.

- Exclusion Criteria- Nurses who were busy in their work.

Written consent was obtained from every participant. Data gathered was kept confidential \& when publishing individual response will be not displayed. Nurses were requested to fill the questionnaire at the home \& return it the next day \& on voluntary basis. The information that I collected from this research project was kept confidential. Information gained were kept locked without sharing with anyone.

\section{Sampling Technique}

Convenient sampling method was used to collect the data for the study. The sample size was taken as about 200 .

\section{Study Instrument and material}


Evaluation of knowledge, attitude and practice of therapeutic communication among nurses were measured using English questionnaires that are developed based on research studies. Questions were analyzed during pilot study and modified accordingly.

\section{Data Collection}

\section{Data collection tools/ instruments}

The data collection tool was the questionnaire which included socio-demographic background, evaluation of knowledge, attitude, practice and causes of failure in therapeutic communication.

\section{Method of collection}

Data was collected during December, 2018. A pre tested questionnaire was given to each nurse after giving brief explanation about the research. Informed written consent was obtained at the same time. Five to 10 minutes were roughly taken to complete the questionnaire for a single participant. All the possible ethical issues were addressed throughout the period of study.

\section{Pre Test}

The questionnaire was pre-tested to clarify comprehensibility \& understanding of questions \& to identify the time required to complete the questionnaire. Twenty-five nurses were selected at Peradeniya hospital who were not included in the proper sample. Furthermore, their wards were not included in the sample too. The questionnaire was modified according to the comments \& data analysis of the pre-test.

\section{Ethical Consideration}

Ethical clearance was obtained from the ethical review committee, Faculty of Allied Health Sciences, University of Peradeniya. Permission to conduct the study was obtained from the Directors of the teaching hospitals of Kandy district, Chief Nursing Officers of each hospital and ward sisters/ ward masters of each ward.

\section{Statistical Analysis}

MINITAB version 18 was used to analyze the data. Catching and correcting errors of the collected data was done before stepping into the data analysis. Non-numerical data was coded into a unique numerical pattern to ease the phase of data analysis. A descriptive analysis along with appropriate visual representation made on the demographics measurements and other interested variables as the first phase in the study. All the hypothesis of the study was conducted at a significant level of 0.05 . Statistical tests for association and goodness of fit was used to assess the significance among the knowledge, attitude and practices. It was determined by employing Chi square test. Further analysis was conducted according to the distributional assumptions on data. 


\section{Results}

\section{Pretest- Validation of the questionnaire.}

The pilot test was carried out using twenty five nurses who were randomly selected from the teaching hospital Peradeniya and not included into the study. The questionnaire was modified according to item analysis by removing and modifying some questions in order to improve the reliability of the study.

Out of the total of 200 nurses who participated in this study, 113(56.5\%) of participants were from the Teaching hospital, Kandy and the majority $79.46 \%$ were females. Forty-three (21.5\%) were from Teaching hospital Peradeniya where $93.02 \%$ of them were females. Forty-four $(22.0 \%)$ participants were from Sirimavo Bandaranaike Specialized Children's Hospital (SBSCH) and all were females. The majority of the participants were thirty years and above in age (76.74\%) in SBSCH. According to analysis, the majority of participants were married. Moreover, majority of participants (59.6\%) receive Rs.41, 000-60,000 as their monthly salary.

Sixty-three percent of the nurses strongly agreed to the fact that active listening is the most important part in therapeutic communication with a patient $\& 36.36 \%$ nurses also agreed with that. Our finding showed that $68.11 \%$ nurses were favorable towards the fact that therapeutic communication technique is not a false reassurance of patient (Table: 1 ).

About $64.64 \%$ of study participants agreed with the fact that therapeutic communication prevents medical errors of patients. Only $1.51 \%$ nurses were in strong disagreement. In addition, about $53.76 \%$ of study participants strongly agreed with the statement that trust, respect \& privacy are important in therapeutic communication. About $55.83 \%$ of participants were in agreement that therapeutic communication can help to relive anxiety of family members. According to results, $51.77 \%$ of participants were with the opinion that therapeutic communication improves self-satisfaction and $46.19 \%$ of participants were in strong agreement.(Table: 2)

Our study showed that, $59.29 \%$ of nurses were always apply therapeutic communication in pre-operative \& post-operative care (Table: 3 ).

There was a statistically significant association between age \& the knowledge that arguing with a patient is not suitable in therapeutic communication. $(p-v a l u e=0.005)$. Moreover, a statistically significant association was observed between education status \& knowledge that therapeutic communication technique isn't false reassurance of patient ( $p$ value $=0.045$ ). Furthermore, there was a statistically significant association between position \& knowledge that arguing with a patient is not suitable in therapeutic communication $(p=0.021)$.

Years of service is one of the most important tools to measure professional experience. Our findings showed that, there was a statistically significant association between years of service \& the knowledge that therapeutic communication helps to encourage the expression of feelings \& ideas of patients $(P=0.005)$. Moreover, a statistically significant association was observed between years of service \& 
knowledge that therapeutic communication involves exchange of information in verbal or non-verbal manner $(\mathrm{P}=0.008)$. and the knowledge that nurses must protect the privacy of patient in order to achieve therapeutic communication ( $p=0.023)$ (Table: 4$)$.

Our finding showed that, there was a statistically significant association between age \& participants' attitude that trust, respect \& privacy are important in therapeutic communication. ( $P=0.045)$ (Table: 5$)$.

Interestingly, the current study reveals that there was a statistically significant association between educational status and the nurse's attitude that he/ she has a responsibility for improving therapeutic communication ( $P=0.010)$ (Table : 5 ).

There was a statistically significant association between graduate form and the attitude that therapeutic communication improves self-satisfaction of nurses $(P=0.011)$ (Table: 5$)$.According to results, similar association was there when position \& years of service were considered. There was a statistically significant association between position \& years of service with attitude of therapeutic communication decreases anxiety and fear of patient $(P=0.008)$ (Table : 5$)$.

Our study showed that, there was a statistically significant association between education status \& participants applying communication to patients with impaired hearing problems $(P=0.009)$. There was also a statistically significant association between position \& application of therapeutic communication in health education $(P=0.0420)$. Furthermore, a statistically significant association between service year \& discussion with family members of patient was also observed $(P=0.024)$ (Table: 6).

As a strong positive fact of the study we found that almost all participants in all three hospitals agreed to promote therapeutic communication in clinical settings.

Our findings showed that over $60 \%$ of participants from Teaching hospitals of Peradeniya \& SBSCH think that therapeutic communication will not increase their workload during the shift. We were unable to identify any statistically significant association.

\section{Discussion}

Therapeutic communication is considered a vital of quality of nursing care. It is described as appropriate care for nurses \& patients. It acts favorably on improving knowledge, attitude \& practice of care by the nurses. Thereby patients can receive satisfactory care from staff in the hospital.

This study was carried out in order to determine the knowledge, attitude \& practice regarding therapeutic communication among nurses in teaching hospitals in Kandy district using self-administered questionnaire.

Our findings showed that, $63.63 \%$ nurses were in strong agreement that active listening is the most important part in therapeutic communication with a patient $\& 36.36 \%$ nurses agreed to the fact. In comparison, another study in Western Ethiopia reported that $94 \%$ nurses were with opinion that 
therapeutic communication helps to succeed the nursing plans(Thanasekaran et al., 2017). A study in an Australian university had attempted assessing nursing students' listening \& communication styles using paper-based versions of the listening style profile. There was only slight differences in preferences for listening and communication styles between the gender (Mckenna et al., 2014). We have identified that nurses in teaching hospitals in Kandy district consider active listening is the most important part in therapeutic communication with a patient. None of the participants stated that active listening is not important in the process. The results could be attributed to the fact that majority of participants were females.

When attitude towards therapeutic communication was considered, majority of participants agreed that therapeutic communication prevents medical errors of patients. According to a study in western Ethiopia, most of the nurses strongly agreed to the fact that therapeutic communication improves their care (Thanasekaran et al., 2017). The results are favorable towards our findings as prevention of medical errors of patients is one part of improving care.

Our study showed that, $59.29 \%$ nurses were always involved in applying therapeutic communication in pre-operative \& post-operative care. Another study showed that majority of nurses utilized therapeutic communication \& results highlighted that $52 \%$ of the nurses always applied the technique in clinical settings (Thanasekaran et al., 2017). Our findings are consistent with their observations.

Our results showed that there was a statistically significant association between socio demographic statuses and knowledge of therapeutic communication. A study in Western Ethiopia reported that there was no statistically significant association between socio-demographic variables and knowledge of therapeutic communication (Thanasekaran et al., 2017). However, we identified that there is an association between attitude towards therapeutic communication and socio demographic variables among study participants. Variables in statistical significant association were age,educational status,graduate form, position, number of years in service and monthly income. The Study in Western Ethiopia showed a significant association between professional status \& attitude of therapeutic communication (Thanasekaran et al., 2017). Furthermore, we also observed an association between socio-demographic variables \& knowledge, attitude and practice regarding therapeutic communication among nurses in our study.

There was a statistically significant association between age \& knowledge that arguing with a patient is not suitable in therapeutic communication. Majority of our participants were aged $>=30$ years. Most of nurses in Sri Lanka join with Ministry of Health at their young age. Their high level of knowledge could be explained as they improve their skills \& knowledge with years of experience.

Further, there was a statistically significant association between education status \& knowledge that therapeutic communication technique isn't false reassurance of patient. Education status is an important qualification to improve patient management skills. Report by Shafakhah et al in 2015 to evaluate nursing students' communication abilities in clinical courses in hospitals in Fatemeh school of nursing \& midwifery in Shiraz, Iran had shown that nursing students who had completed higher semester had better 
communication skills than students in lower semesters(Shafakhah et al., 2015). Similarly another study in Greek had confirmed that there is a statistically significant association between nurses learning at the university and those with two years training. Nurses at the University responded with higher number of correct answers about communication than others(Kounenou, Aikaterini and Georgia, 2011). As a result of the changes in the curriculum, continuing education programs, nurses in our country too have improved their skills \& knowledge on patient care including facts on therapeutic communication. There was also a statistically significant association between positions \& the knowledge that arguing with a patient is not suitable in therapeutic communication.

We observed a statistically significant association between number of years of service \& knowledge that therapeutic communication helps to encourage expression of feelings \& ideas of patients and exchange of information in verbal or non-verbal manner and nurses must protect the privacy of patient in order to achieve therapeutic communication. Furthermore, according to our study, there was a statistically significant association between number of years in service and knowledge of therapeutic communication. However, another study had shown that there is no statistically significant association between years of service \& knowledge of therapeutic communication. We consider number of years in service is an important tool to show the level of experience of nursing practice.

In addition, there was a statistically significant association between socio-demographic variables and attitude of therapeutic communication. Our finding also showed that, there was a statistically significant association between age \& attitude that trust, respect \& privacy are important in therapeutic communication. Interestingly, we observed a statistically significant association between educational status and the nurse feeling that he/ she has a responsibility to improve therapeutic communication. There was also a statistically significant association between graduate form and attitude that therapeutic communication improves self-satisfaction of nurses. A statistically significant association was identified between position \& number of years in service with attitude that therapeutic communication decreases anxiety and fear of patient. Shafakhah et al in their study showed that there was a significant association between nursing students' clinical communication behavior scores \& treatment communication ability(Shafakhah et al., 2015) .It also has highlighted that there was a significant association between the students' educational semester \& their clinical communication behavior \& treatment communication (Shafakhah et al., 2015). The findings are confirming our results. We can intrepret statistically significant association between age,educational status,graduate form,position \& service year and attitude of therapeutic communication of nurses in Kandy district as most of the participants were married and living with families bound with Sri Lankan culture understand patients' feelings and emotional levels than individuals living isolated like in some countries.

There was a statistically signifiacant association between education status and applying therapeutic communication to patients with impaired hearing problems. We also identified a statistically significant association between position and applying therapeutic communication in health education and a statistically significant association between number of years in service and discussion with family members of patients. We can summerize that there was a statistically significant association between 
educational status,position \& number of years in service and knowledge, attitude \& practice of therapeutic communication among study participants.

Our finding showed that majority of participants in Teaching hospital in Kandy think that therapeutic communication will increase their workload. However, over $60 \%$ of participants from Peradeniya \& SBSCH were favorbale towards the fact that therapeutic communication will not increase their workload during shift. Similarly, 39\% of the nurses had complained of lack of time as the reason for their poor practice (Thanasekaran et al., 2017). Maame et al.,2018 had also identified that high workload is the major barrier for successful therapeutic communication by nurses(Maame et al., 2018). We an describe the similar reason for the Teaching hospital in Kandy as its patient output is higher than other two hospitals. We consider it as a positive fact that almost all participants from all three hospitals agreed to promote therapeutic communication. We consider this study is an important step in assessing various aspects of therapeutic communication in Sri Lankan hospitals.

\section{Conclusion}

There was a statistically significant association between educational status,position \& number of years in service and knowledge, attitude \& practice of therapeutic communication among study participants. Active listening is considered the most important part in therapeutic communication which prevents medical errors of patients.

Fifty-nine percent of the nurses in Teaching hospitals in Kandy always apply therapeutic communication in pre-operative \& post-operative care. Majority agree to promote the therapeutic communication in their clinical setting. However, they consider that therapeutic communication would increase their workload. It is suggested that the workload in Kandy hospital is to be fairly distributed in order to arrange a friendly environment in the hospital setting to allow more time for practice of therapeutic communication which ultimately will improve nursing outcome.

\section{Declarations}

\section{Ethics approval and consent to participate}

Ethical clearance was obtained from the ethical review committee, Faculty of Allied Health Sciences, University of Peradeniya.

\section{Consent for publication}

Not applicable

\section{Availability of data and material}

The datasets used and/or analysed during the current study are available from the corresponding author on reasonable request. 


\section{Competing interests}

The authors declare that they have no competing interests

\section{Funding}

Authors declare that there was no funding resource for the study.

\section{Authors' contributions}

DMDD made the major contribution by writing the initial draft of the research proposal, obtaining permission, carrying out the research, writing initial draft and making the tables in order. RMJ contributed in identifying research question, assessing and correcting research proposal, draft of the manuscript, assessing results, arranging the manuscript according to guidelines and overall supervision of the research work. SA contributed in analyzing results of the study, assessing methods and results of the study. All authors read and approved the final manuscript.

\section{Acknowledgements}

Not applicable

\section{References}

Bramhall, E. (2014).Prepare for revalidation: read this CPD article and write a reflective account http://revalidation.zone.29:53-59.

C, M. V. P. and George, P. S. (2014). Effectiveness of Structured Teaching Module on Therapeutic Communication among staff nurses .3:27-31.

Ferreira ${ }^{a}$, M., Silva, D., Pires, A., Sousa, M. and Calheiros, N. (2016).Clinical Skills and Communication in Nursing Students.

Indirawaty, H. and Ab, S. (2015).Nurse Interaction With Clients In Communication Therapeutic ( Study Analysis Of Symbolic Interactionism Hospital South Sulawesi ). 4.

Maame, V., Amoah, K., Anokye, R., Boakye, D. S. and Gyamfi, N. (2018) .Perceived barriers to effective therapeutic communication among nurses and patients at Kumasi South Hospital. Cogent Medicine. Cogent22: $1-12$

Mckenna, L., Brown, T., Boyle, M., Williams, B., Palermo, C. and Molloy, E. (2014) .Listening and communication styles in nursing students.4: $50-58$

Miguel, N. T. (2014) .Therapeutic Relationship of Staff Nurses with Medical Patients: Basis for In-Service Training Program. 1: 15-21. 
Negi, S., Kaur, H., Singh, G. M. and Pugazhendi, S. (2017) .Quality of nurse patient therapeutic communication and overall patient satisfaction during their hospitalization stay. 6 : 675-679.

Shafakhah, M., Zarshenas, L., Sharif, F. and Sarvestani, R. S. (2015) .Evaluation of Nursing Students' Communication Abilities in Clinical Courses in Hospitals. 7 : 323-328.

Thanasekaran, P., Yadecha, B., Upashe, S. P. and Chala, D. (2017) .Knowledge , Attitude and Practice Regarding Therapeutic Communication among Nurses in Selected Government Hospitals in Oromia , Western Ethiopia , 2016.6: 159-164.

Therapeutic communication.(2013). 4 pp. 457-466.

Younis, J. R. (2015) .Effect of the planned therapeutic communication program on therapeutic communication skills of pediatric nurses. 5:pp. 109-120.

\section{Tables}

Table : 1 Percentage of knowledge among the study participants, Kandy district

\begin{tabular}{l|l|l|l|l|l|}
\hline $\mathrm{N}$ & Variables & $\begin{array}{l}\text { Strongly } \\
\text { agree } \\
(\%)\end{array}$ & Agree & Disagree & $\begin{array}{l}\text { Strongly } \\
\text { disagree }\end{array}$ \\
\hline $\begin{array}{l}\text { Therapeutic communication helps to } \\
\text { encourage the expression of feelings \& } \\
\text { ideas of patients. }\end{array}$ & 47.96 & 52.04 & - & - \\
\hline $\begin{array}{l}\text { Active listening is the most important part } \\
\text { in therapeutic communication with a } \\
\text { patient. }\end{array}$ & 63.63 & 36.36 & - & - \\
\hline $\begin{array}{l}\text { Empathy is the ability to understand \& } \\
\text { accept another person's reality }\end{array}$ & 31.28 & 63.07 & 5.64 & - \\
\hline $\begin{array}{l}\text { Therapeutic communication technique is } \\
\text { not a false reassurance of patient. }\end{array}$ & 15.13 & 68.11 & 14.05 & 2.70 \\
\hline $\begin{array}{l}\text { Arguing with a patient is not suitable in } \\
\text { therapeutic communication. }\end{array}$ & 33.67 & 54.59 & 9.18 & 2.55 \\
\hline $\begin{array}{l}\text { Arguing with a patient might make to tell } \\
\text { lies and misinformation. }\end{array}$ & 18.04 & 57.21 & 20.61 & 4.12 \\
\hline $\begin{array}{l}\text { Therapeutic communication involves the } \\
\text { exchange of information in verbal or non- } \\
\text { verbal manner. }\end{array}$ & 33.67 & 61.6 & 3.62 & 1.03 \\
\hline $\begin{array}{l}\text { To achieve to the therapeutic } \\
\text { communication nurses } \\
\text { must protect the privacy of patient. }\end{array}$ & 64.10 & 34.87 & 1.03 & - \\
\hline
\end{tabular}


Table: 1 shows the level of knowledge on therapeutic communication among participants of the study

Table: 2 Percentage of attitude among the study participants, Kandy district.

\begin{tabular}{l|l|l|l|l|l|}
\hline S.N & Variable & $\begin{array}{l}\text { Strongly } \\
\text { Agree }\end{array}$ & Agree & Disagree & $\begin{array}{l}\text { Strongly } \\
\text { disagree }\end{array}$ \\
\hline 1 & $\begin{array}{l}\text { Therapeutic communication improves self- } \\
\text { satisfaction of nurses. }\end{array}$ & 46.19 & 51.77 & 2.03 & - \\
\hline 2 & $\begin{array}{l}\text { Therapeutic communication decrease } \\
\text { anxiety, fear of patient. }\end{array}$ & 44.38 & 48.46 & 6.12 & 1.02 \\
\hline 3 & $\begin{array}{l}\text { Therapeutic communication prevents } \\
\text { medical errors of patients. }\end{array}$ & 23.73 & 64.64 & 10.10 & 1.51 \\
\hline 4 & $\begin{array}{l}\text { Therapeutic communication helps } \\
\text { continuous nursing care for patients. }\end{array}$ & 39.19 & 59.29 & 1.50 & - \\
\hline 5 & $\begin{array}{l}\text { Trust, respect \& privacy are important in } \\
\text { therapeutic communication. }\end{array}$ & 53.76 & 45.22 & 1.00 & - \\
\hline 5 & $\begin{array}{l}\text { The nurse has a responsibility for improve } \\
\text { therapeutic communication. }\end{array}$ & 48.98 & 50.50 & 0.50 & - \\
\hline 7 & $\begin{array}{l}\text { Therapeutic communication can help to } \\
\text { relive anxiety of family members. }\end{array}$ & 42.13 & 55.83 & 2.03 & - \\
\hline
\end{tabular}

Table: 2 shows the attitude on therapeutic communication among participants of the study

Table: 3 Percentage of participants practicing therapeutic communication in Kandy district. 


\begin{tabular}{|l|l|l|l|l|l|}
\hline S.N. & Variables & Always & Sometimes & Occasionally & Never \\
\hline 1 & $\begin{array}{l}\text { Apply therapeutic communication in } \\
\text { health education. }\end{array}$ & 38 & 55 & 7 & - \\
\hline 2 & $\begin{array}{l}\text { Apply therapeutic communication in } \\
\text { preoperative \& post-operative care. }\end{array}$ & 59.29 & 28.64 & 11.55 & 0.5 \\
\hline 3 & $\begin{array}{l}\text { Apply therapeutic communication in } \\
\text { admission of patient in ward. }\end{array}$ & 58.5 & 31.5 & 8.5 & 1.5 \\
\hline 4 & $\begin{array}{l}\text { Apply communication to patients with } \\
\text { impaired hearing problems. }\end{array}$ & 29.64 & 52.76 & 14.57 & 3.01 \\
\hline 5 & $\begin{array}{l}\text { Apply therapeutic communication } \\
\text { after admission of patient. }\end{array}$ & 51.25 & 40.70 & 7.03 & 1.00 \\
\hline 6 & $\begin{array}{l}\text { Discussion with family members of } \\
\text { patient }\end{array}$ & 41.41 & 46.96 & 10.10 & 1.51 \\
\hline
\end{tabular}

Table: 3 shows the frequency of practice of therapeutic communication among participants of the study

Table: 4 Association of knowledge on therapeutic communication with socio demographic variables among nurses, Kandy district. 


\begin{tabular}{|l|l|c|}
\hline $\begin{array}{l}\text { Socio } \\
\text { demographic } \\
\text { Variable }\end{array}$ & Variable & $\begin{array}{l}\text { P- } \\
\text { Value }\end{array}$ \\
\hline Age & $\begin{array}{l}\text { Arguing with a patient is not suitable in therapeutic } \\
\text { communication. }\end{array}$ & 0.005 \\
\hline $\begin{array}{l}\text { Educational } \\
\text { Status }\end{array}$ & $\begin{array}{l}\text { Therapeutic communication technique is not a false } \\
\text { reassurance of patient }\end{array}$ & 0.045 \\
\hline Position & $\begin{array}{l}\text { Arguing with a patient is not suitable in therapeutic } \\
\text { communication. }\end{array}$ & 0.021 \\
\hline Service year & $\begin{array}{l}\text { Therapeutic communication helps to encourage the } \\
\text { expression of feelings \& ideas of patients. }\end{array}$ & 0.005 \\
\hline Monthly Income & $\begin{array}{l}\text { Therapeutic communication involves the exchange of } \\
\text { information in verbal or non-verbal manner. }\end{array}$ & $\begin{array}{l}\text { Active listening is the most important part in therapeutic } \\
\text { protect the privacy of patient. }\end{array}$ \\
\hline
\end{tabular}

${ }^{* *}$ Tests of significance done by chi-square test $\mathrm{p}$ value $<0.05$ is significant

Table: 4 shows the association of knowledge on therapeutic communication with socio economic background of the participants of the study

Table: 5. Association of attitude on therapeutic communication with socio demographic variables among nurses, Kandy district. 


\begin{tabular}{|l|l|l|}
\hline $\begin{array}{l}\text { Socio-demographic } \\
\text { variables }\end{array}$ & Variables & $\begin{array}{l}\text { P- } \\
\text { value }\end{array}$ \\
\hline Age & $\begin{array}{l}\text { Trust, respect \& privacy are important in therapeutic } \\
\text { communication. }\end{array}$ & 0.045 \\
\hline Educational Status & $\begin{array}{l}\text { The nurse has a responsibility for improve therapeutic } \\
\text { communication. }\end{array}$ & 0.010 \\
\hline Graduate Form & $\begin{array}{l}\text { Therapeutic communication improves self-satisfaction of } \\
\text { nurses. }\end{array}$ & 0.011 \\
\hline Position, Service year & $\begin{array}{l}\text { Therapeutic communication decrease anxiety, fear of } \\
\text { patient. }\end{array}$ & 0.008 \\
\hline Monthly Income & $\begin{array}{l}\text { Therapeutic communication decrease anxiety, fear of } \\
\text { patient. }\end{array}$ & 0.012 \\
\hline
\end{tabular}

**Tests of significance done by chi-square test $\mathrm{p}$ value $<0.05$ is significant.

Table: 5 shows the association of attitude on therapeutic communication with sociodemographic variables of participants of the study

Table: 6 Association of practice of therapeutic communication with socio demographic variables among nurses, Kandy district.

\begin{tabular}{|l|l|l|}
\hline $\begin{array}{l}\text { Socio-demographic } \\
\text { Variables }\end{array}$ & Variables & $\begin{array}{l}\text { P- } \\
\text { Value }\end{array}$ \\
\hline Educational Status & $\begin{array}{l}\text { Apply communication to patients with impaired } \\
\text { hearing problems }\end{array}$ & 0.009 \\
\hline Position & Apply therapeutic communication in health education & 0.042 \\
\hline Service Year & Discussion with family members of patient & 0.024 \\
\hline
\end{tabular}

**Tests of significance done by chi-square test $\mathrm{p}$ value $<0.05$ is significant

Table: 6 shows the association of practice of therapeutic communication with sociodemographic variables of the participants of the study 